\title{
The politics of Widowhood and Re-Marriage among the Luo of Kenya
}

\author{
SAMSON O. GUNGA \\ Department of Educational Foundations \\ University of Nairobi, Kenya \\ gungasamson@googlemail.com \\ Thought and Practice: A Journal of the Philosophical Association of Kenya (PAK) \\ Premier Issue, New Series, Vol.1 No.1, June 2009, pp.161-174 \\ thoughtandpractice@uonbi.ac.ke OR thoughtandpractice@gmail.com
}

\begin{abstract}
This study utilises philosophical deliberation to analyse the psycho-social and emotional conflicts that arise out of widowhood practices in the Luo community of Kenya. Towards this end, it explores the attendant effects of Luo widowhood practices on family, power and gender relations, and suggests resolutions to the challenges they generate.
\end{abstract}

\section{Introduction}

The death of a spouse is a moment of devastation and sadness due to loss of love, care, company and livelihood, attended by a feeling of abandonment. It represents not simply the departure of a friend and sometimes a breadwinner, but also results in a radical change in one's social status and lifestyle. In the Luo community in Kenya, the attempt to create normalcy after the death of a spouse by embracing specific coping mechanisms has ramifications that create challenges which need serious attention. Issues of death are generally emotive, and the situation is made worse when the process of re-adjustment to the new scenario created by bereavement is controlled by pre-defined cultural forces that one may not understand. Widowhood rituals in the 
Luo community have often taken centre stage in the community's politics, especially when such practices are perceived to expose surviving spouses, particularly widows, to certain levels of indignity.

This study utilises philosophical deliberation to analyse the psycho-social and emotional conflicts that arise out of widowhood practices in the Luo community of Kenya. Towards this end, it explores the attendant effects of Luo widowhood practices on family, power and gender relations, and suggests resolutions to the challenges they generate. The paper first reflects on various dominant views concerning the significance of death. Next, it examines bereavement in Luo culture, before focusing on socialisation in widowhood among the Luo. Finally, the paper examines ways in which Luo widows could be empowered socially and economically, in a bid to emancipate them from destructive widowhood rituals. The Luo are of Nilotic origin, and migrated south into Kenya from Egypt and Sudan via Uganda approximately 1500-1800 C.E. They live within $60 \mathrm{~km}$, on average, around Lake Victoria.

\section{The Significance of Death}

The finality of death (cessation of personal survival) is feared by people in cultures all over the world. Archaeological evidence shows that death has influenced cultures, behaviour, beliefs and attitudes of people since pre-historic times. Our inability to control and make death do our bidding is maddening. In his book, The Meaning of Death (1959), Herman Feifel hypothesizes that by removing the taboo nature of dying and death, it might lose some of its fearful qualities, and allow people to lead more fulfilling and healthier lives. To do this, we need to understand death itself, acquire knowledge of its ramifications, and change our perception about it in our lives. The fact that "where people go after death" is clouded in speculative answers creates worries and controversies. The consciousness we have of our potential or actual capacities toward achievement of self-regard through physical existence keeps us in want of a self-being in perpetuity. 
Even if people do not go anywhere after death, the fact of cessation of physical existence, and that we cannot do anything about it, is terrifying. People do not want to believe that human beings die and perish like every other living thing (both plants and animals), and would rather look for answers that give hope regarding human destiny. Attempts to understand what constitutes death (Green and Winkler 1980) may be compared with attempts to understand what our existence or non-existence before birth entails. Just as my actual existence, potential existence or none existence before birth is neither bad nor good to anybody, so is my position in death, despite the confounding fact that in birth I come from a human body and in death I disappear into the soil or elsewhere. My position in pre-life (before birth) neither bothered me nor anybody else including my parents. Analogously, my position in post-life need not bother my spouse and friends, as I seem to revert to a state equivalent to my pre-life position.

While my existence in life creates a special bond that never existed before my birth, the fear of my death, my friend's or my spouse's death is useful only in as far as it provides an opportunity for me, my spouse or friends to face the inevitable death of one or several of us. Other than the survivors' feelings of loss occasioned by the levels of emotional and practical dependency engendered by the deceased's previous physical presence in their lives, there does not seem to be any other harm that death causes, as one reverts to a state similar to "before birth". Due to the deceased's nonexistence, the loss of all the things that one (the deceased) enjoyed in life is not felt, and therefore is of no consequence. The feelings of loss that we (the survivors) do express in grief are apparently normal, and we may choose to control their impact and effect in our lives in the shortest time possible. 
Although, in our sub-conscious, we do not want to die (Kamm 1998) as a way of nurturing a sense of self-preservation, it is irrational to believe that one may outlive everyone born within one's lifetime, a notion nurtured by many, for that would be akin to immortality. While the reality is that every intimacy with, or dependency on, another person shall be terminated by death of one of the parties, many people hardly "prepare" for the inevitable departure of one of them through death. Instead, they hope that nothing of the sort will happen soon, a kin to the proverbial burying the head in the sand.

Jacques Derrida (1998) argues that the basis of all friendship is mourning. The fundamental law of friendship and intimacy is that one must die before the other - that there is no friendship without this inevitability. Consequently, marriage is a temporal institution - it ends at the death of one of the spouses, and this is a certainty that must be endured. Death serves as the true expression of love, because it acts as an intensifier and ennobler of love lost (Gordon-Smith 2008), and hence when someone one loves no longer lives, love becomes heightened, idealized, and preserved in memory. This preservation should, ideally, be reflected in a continual preparation for the possibility of a partner's death. However, what does preparation for the inevitability of a friend's departure consist in? This is not a piece of advice to husbands and wives to seek for standby spouses!

Probably, it is the impact on us of the feelings we have about death, and our beliefs about the perceived situation of the deceased, that affect our coping mechanisms. To what extent and for how long can one value the perceived personhood of a deceased individual? My life must continue even after the death of my spouse, and it is my responsibility to shape it if I view myself as a separate entity from the deceased.

\section{Bereavement in Luo culture}

As in many African communities, death in the Luo community is seen as a great and irredeemable tragedy even when such death occurs in old age. It is even a greater tragedy when it occurs in middle or tender age. Unlike the birth of a child, death is 
hardly seen as fully natural, and just as in West Africa, when the death is of a young person, 'all restraints are thrown overboard and explanation sought in witchcraft, juju or bad medicine' (Sossou 2002). Widowhood as a bereavement is a natural occurrence associated with grief. In many societies, widowhood is a process characterized by rituals, forced remarriages, harassment, rejection, loneliness, poverty, loss of status, fear of the future and depression (Ntozi 1997). The degree of expression of the negativities depends on the communities' culture, religion and economic systems:

... widowhood practices are closely tied to cultural and traditional beliefs about death,
ghosts, inheritance, feminine roles, family structure and family relationships. The
overpowering belief in the ability of the ghost of a dead person to come back to
dispute and haunt all kinds of things and relatives has reinforced and perpetuated the
age-old practices of widowhood in Africa... The belief that death brings corruption
and the dead still have contact with the living, especially their closest partners in life,
is one of the reasons used for subjecting widows to inhuman and humiliating
customary practices. The satisfactory completion of these ceremonies, rituals and
practices is therefore believed to help restore the balance and security, which the
death had sought to overthrow. The people, due to superstitious beliefs, rationalise
these practices with the argument that they perform important functions, such as
giving the widows protection from their powerful deceased husbands (Sossou 2002).

In various cultures throughout the world, and in particular in sub Saharan Africa, women are forced to undergo various rituals after the death of their spouses (COHRE \& WHRP 2008). Luo widows are not permitted to formally remarry or take other sexual partners in addition to the surrogate husband (Potash 1986a, 1986b); Kirwen 1979). Just as in the lower castes of Haryana of India (Chowdhury 1994), Luo widows are encouraged to get a surrogate husband within the family of the deceased husband through ter (culturally-sanctioned"re-marriage"), a situation that has often been controversially referred to as "wife inheritance" or "widow inheritance". Through ter, as a Luo cultural practice, a male relative of the deceased takes over the guardianship of the deceased's family, including the wife (COHRE \& WHRP 2008), so that the deceased's inherited property stays in the family (Ntozi 1997). However, in the Luo culture, the widow remains the wife of the deceased, and not the wife of the guardian or "inheritor". The Luo practice of ter entails cleansing as a pre-requisite for restoring normalcy of the widow into the society, and as a means of neutralising the assumed cultural impurity and avoiding chira or taboo violation: 
...women are expected to observe a cleansing ritual, which has a sexual component, before being re-incorporated into society.... a widow was confined to her homestead for a whole year, since she was considered as culturally impure and dangerous to the community. During this time, a widow had a dream where she engaged in sex with the deceased. The sex dream was an indicator that the widow was free to be cleansed. Indeed, widowhood taboos were lifted after the final post-burial ritual where the life of the deceased was celebrated. Thereafter, widows were given to men in the community to guard them, with a view to providing material and emotional needs. This ritual endangers the lives of widows and their new sexual partners through possible infection with HIV/AIDS. If the family suspects that the death was related to HIV/AIDS, it hires a professional cleanser, and gives him alcohol. Thereafter, he is taken to the widow's house to perform a sex ritual on her. Family members sometimes supervise the ritual, to ensure that actual sexual intercourse takes place, thereby effecting the cultural cleansing. Sex is a must. This is because the prime function of cleansing is both to free the widow from okola (bondage), and to enable her to get children so as to perpetuate the deceased's lineage. A professional cleanser, jakowiny, clears all possible ritual obstacles in readiness for the guardian to take over the widow .... (Ambasa-Shisanya 2007).

Sex is central to the cleansing ritual (Kunda 1995; Butlerys et al. 1994; Luginaah, Elkins, Maticka-Tyndale, Landry \& Mathui 2005). It is a prelude to placing a widow under guardianship, and is performed by a professional cleanser. The "ritual cleansing" (chodo okola) is achieved through obligatory sexual intercourse, performed by jatiek kwer if he is from within the clan, or a jakowiny when he is an outsider (Kimani 2004). Ocholla-Ayayo (1996, 4) observes that a jakowiny, a sexual perverse, or psychopath capable of doing what normal human beings cannot do, is persuaded to perform a sexual cord cutting ritual to separate the widow from her deceased husband, so that the widow may be free to re-marry or to be inherited. It is preferable that he be an outsider, because his undertaking to cleanse the widow means his assuming the state of contamination or "uncleanness", thus accepting to be separated from the clan much like the sacrificial lamb that takes on the blemish of the offender (Kimani 2004).

Although widowhood rituals are intended as ways of showing public respect for the dead and proof of the inconsolable sadness of the widow, they expose the widows to psycho-emotional and physical indignity as discussed above. The fundamental social change in her lifestyle is dramatised, emphasising her faithfulness to her husband's memory, and her chastity during the marriage period. The moral justification of widowhood rituals among the Luo is for the purpose of meeting the perceived needs of the dead, his living relations and dependants. The psychological fear of defiling children with cultural impurity, chira, and the subsequent desire to neutralise it, are the driving forces for cleansing rites. 
While in re-marriage the woman may relocate to live with the new husband after undergoing a fresh round of marriage rites, inheritance refers to a situation where the "new husband" acts for the deceased, as the latter remains the undisputed husband in death. The inheritor (jater) is normally a brother or a close male relative of the deceased, and the decision of the survivor (widow) in this regard, is culturally compelled rather than self-willed, a situation that creates problems in adjusting to the new scenario within the community.

In its original form, wife inheritance was meant to guard against a stranger husband introducing alien character traits in the family by siring offspring whose demeanour could be perceived to be contrary to what is expected in the deceased's homestead. The "inheritor" serves as the widow's sole legitimate sexual partner (Luke 2001). He functions as a husband in all respects, including acting as the father figure during the marriage of the widow's children.

Whereas widows are subjected to very strenuous widowhood rites among the Luo, widowers are not. In a similar fashion to Owen's (1994) observation, bereaved Luo men may interact freely in the community and are therefore more likely to remarry out of choice, because their movements are not unduly restricted by widowhood rites. In the few instances where men are also required to undergo some "cleansing rituals", the procedures are much simpler than what their female counterparts experience (Limann 2003). Far more restrictions are placed on a widow than a widower (Sossou 2002).

The enforcement of widowhood rituals has been vested in elderly married women and widows. They have been psyched into believing that the rituals are for the widows' benefit and those of their children. With fellow women in charge of the situation, young widows are silenced into submission (Sossou 2002), as they are taken through the observation of the rites as "willing" participants. 


\section{Socialization in widowhood}

The purpose of marriage in sub-Saharan Africa is reproduction, and marriage is defined as the transfer of a woman's reproductive rights from her father to a husband (Caldwell 1976, 361; Caldwell \& Caldwell 1987, 420). Since a man acquires reproductive rights at marriage, he typically makes all fertility decisions (Tertilt 2005). Men prefer to marry women who are significantly younger, because this will make them more submissive (Tertilt 2005).

The Luo culture is patrilineal and patrilocal, and hence family life is centred on the lineage as defined through male descendants. Upon marriage, a woman moves to where her husband's family is located (Tertilt 2005). Among the Luo, inheritance and residence are also centred on the male lineage, and men are the major decision makers and controllers of wealth and power. Upon marriage, husbands and families exchange bridewealth for the reproductive and productive capabilities of women (Cohen \& Adhiambo 1989; Okeyo 1980; Ocholla-Ayayo 1976). Marriage is therefore considered actualized when the woman relocates to a geographical place of residence agreeable to the man. It is therefore a common saying in the Luo that marriage is not a mutual affair: the man marries the woman, and the woman gets married to the man in reference to the idea of relocation of the woman. Consequently, virtually all power lies in the hands of the elderly males. Men make most decisions, which women are expected to follow, and a man is expected to be the head of the family.

Immediately on the death of a spouse, an investigation is launched to check if the two were properly married. The use of bridewealth in marriage is a common practice in the Luo community. In a majority of African ethnic groups, bridewealth is imperative for the legitimacy of a marriage to be recognized (Getz 1995, 14; Makisi 1995, 16; Mwamwenda 1995). Although the "come we stay" (cohabitation) phenomenon currently threatens the payment of bridewealth thus undermining the stability of marriages, it is generally believed that commitment to paying bridewealth is an indication of an equal commitment to the sustainability of the marriage. The bridewealth serves various purposes, some of which are that it heightens (a) a 
husband's gratitude for a good wife, (b) his appreciation of the wife's dignity and worth, and (c) the wife's assurance of her husband's continued recognition and respect (Mwamwenda \& Monyooe 2007). It also helps to control both the number of women available for marriage (since polygyny is allowed by the Luo culture) to the same man and the rate of divorce (Mwamwenda \& Monyooe 2007).

No marriage is recognized by both families of the bride and the groom if the man never paid the bridewealth. In the event that a husband dies before paying bridewealth for his wife, the brother's in-law of the wife or other relatives of the deceased husband must pay the bridewealth, or the woman may choose to go back to her parents. If it is the wife who has died, the husband must pay the bridewealth before he is allowed to bury her as his wife. Payment of bridewealth by a husband is a demonstration that the man has come of age, and has not only the capability to support himself and his wife, but also the level of commitment recognized to sustain the marriage. Acceptance of the bridewealth signifies the families' recognition, authentication, support and blessing of the union, and seals it in life and in death.

Once it is proved that the marriage was properly consummated, the widow acquires permanent acceptance in the home, and if it is the man who survives her, then he is now allowed to undertake the widowhood rights. If it is the woman who survives, she is now in a position to find a relative to her dead husband, who will perform various duties for the deceased husband. This is in preparation to go through cultural rights associated with widowhood. The Luo social structure shows a gender division of roles and responsibilities. Certain duties such as building houses, for instance, must be undertaken by a man, while duties such as cooking for the family ought to be undertaken by a woman. These gendered roles sometimes change in widowhood. Although Luo widows maintain a high degree of autonomy and have a say in the choice of their inheritors, they usually continue to reside in their deceased husbands' homesteads, instead of relocating to the residence of their inheritors (Ndisi 1974). They have no domestic responsibilities toward the inheritor, despite the fact that the inheritor may help the widow with ploughing, school fees or building a house as nonformal duties, depending on the relationship between the couple (Potash 1986b). 
The community within which a widow lives can help her overcome much of her sadness. In most cases, acceptance of the widow after the death of a husband depends on her cooperation with regard to the dictates concerning the cultural rites of widowhood. In addition, the widow's adjustment to her new status depends on the support she gets from the family of her late husband, whose attitude towards widowhood is an important factor. Finally, if a widow possesses adequate material resources, she can reduce her vulnerability to exploitation.

\section{Widowhood empowerment scheme}

Empowerment is the means through which people reduce their helplessness and alienation in order to gain greater control over all aspects of their lives and social environment (Simon 1990). It involves attacking all forms of subordination in human lives. The inhibitions could be psychic, physical, cultural, sexual, legal, political, economic and even technological. Consequently, resolutions of the problems posed require a multi-dimensional approach that must improve psycho-social, educational, cultural, spiritual and emotional development. One must be assisted to recognize and understand one's disadvantaged situation in order to be aided to take steps to overcome it. Through social widowhood education, men and women can be enabled collectively and individually to take full control over their lives and situations so as to overcome problems of irrational beliefs, superstition, ignorance, illiteracy and psychological suppression. According to Lopata (1979), in order for widows to be integrated into the support systems of their communities, they need a friendly culture which specifies dignified ways in which the community expects them to behave, and how they should be treated by their kin and those of their deceased husbands.

Widowhood entails emotional loss and change in lifestyle, identity, social status and role (Zahedi 2006). Consequently, socio-economic and emotional support provided by the family, community and society at large highly impact on widows and widowers in identifying and utilising coping mechanisms. Although the family should be encouraged to play a more central role in assisting widows in particular, alternative support systems should be developed to help the widows in case the family is not co- 
operative (Ntozi 1997). It is personal and collective empowerment and transformative approaches that can help widows to take control of their own lives and destinies (Sossou 2002). Transformative approaches involving men of influence who understand the situation, village elders, individual women and women groups are necessary in the struggle for the eradication of negative widowhood practices in the Luo cultural system. The empowerment process is complex, and involves a holistic approach to dealing with personality and the social environment. It entails providing an enabling environment for the bereaved to negotiate his/her role in the restoration of normalcy after losing a spouse.

Widows in rural Luo communities in Kenya are subjected to destructive rites due to their relative vulnerability, low literacy and lack of exposure. Many of them who have no source of income find it difficult to resist being "inherited" for fear of excommunication from their matrimonial homes, without any entitlements to the estates of their deceased husbands. This is in sharp contrast to urban Luo women, who are largely enlightened and therefore independent (Limann 2003; Ambasa-Shisanya 2007). There is evidence that most rural Luo widows with secondary school education and economic stability ignore the cultural requirement of guardianship. On the other hand, widows with primary school education and no economic empowerment more readily submit to such cultural demands. Thus intervention through education has helped Luo widows and widowers to refrain from life threatening widowhood rituals. Without adequate education, even knowledge about HIV/Aids does not always translate into behaviour change (NASCOP 2005; Ocholla-Ayayo 1996). Most men, especially those with lower school education, insist on having sexual relations with widows, even after being warned about their HIV status (Ambasa-Shisanya 2007).

Another empowerment approach is legal literacy, which aims at creating awareness through human rights education among different stakeholders in the society. Apart from education and economic empowerment, there is a need to improve legal structures so that widows can inherit the property of the deceased directly, instead of owning it through their sons, as is the case in the Luo community today. This will prevent widows from risking their health for the sake of property. Legal literacy may be used to enhance the rights of widows in the society by engaging the participation of stakeholders who are perceived to perpetuate such rights. These would include 
heads of families, village elders (men and women), widows and widowers among others.

In order for the exercise not to be seen as politics against the community, those who popularize the change to embrace new ideas must be people who are respected by the community. Such persons will provide assurance that the need for change is timely, and that it is for the benefit of the community itself. A good example of this has been seen in 2008 when the perceived Luo leader Raila Amollo Odinga (2008) joined the debate on circumcision as one means of reducing the impact of HIV pandemic. The response was instant and overwhelming. Luo men trooped to health centres to have the cut, for they believed that once their leader had endorsed the idea, then it was good for them. This is an indication that the Luo are receptive to change, as long as it is effectively popularized through recognized change agents such as politicians, cultural institutions and village-elder fora.

\section{Conclusion}

It is natural for one to grieve for the death of a loved one. This is due to the fact that death presents a situation in which one loses the power of negotiation, since it is beyond human control. The survivor's helplessness is made worse if, as is the case for many rural Kenyan Luo widows, the loss of the capacity to negotiate is extended to the activities that are meant to restore normalcy to them. However, with a positive disposition, such widows can get an opportunity for growth, and discover aspects of their personalities that facilitate their own empowerment. As Packer $(1995,32)$ puts it, one must go through widowhood to a place where it is no longer a feeling of the pain of loss, but an understanding of the loss based on a belief system that one has established to ensure rational, emotional and psychological stability. Rural Kenyan Luo widows must therefore be helped to face their grief, to live through it in a way that integrates their experiences into their personalities, and thereby to gain control over their destinies. 


\section{References}

Ambasa-Shisanya, C.R. 2007. "Widowhood in the era of HIV/AIDS: A case study of Siaya District, Kenya". Journal of Social Aspects of HIV/AIDS, Vol.4 no.2.

Butlerys, M., F. Musanganire, A. Chao, A. Saah and A. Dushimimana. 1994. "Traditional mourning customs and the spread of HIV-1 in rural Rwanda: a target for AIDS prevention?" (Letter). AIDS Vol.8 no.6, pp.858-859.

Caldwell, John C. 1976. "Marriage, the Family and Fertility in Sub-Saharan Africa, with Special Reference to Research Programmes in Ghana and Nigeria”. In Family and Marriage in Some African and Asiatic Countries. Ed. Suliman

Caldwell, John C. and Pat Caldwell. 1987. "The Cultural Context of High Fertility in Sub-Saharan Africa". Population and Development Review, 13, pp.409-437.

Chowdhury, P. 1994. "Widow remarriage in Haryana: Law strengthens repressiveness of popular culture". Manuscript Abstract, Popline.

Cohen, David William and E.S. Atieno Odhiambo. 1989. Siaya: The Historical Anthropology of an African Landscape. London: James Currey.

Derrida, Jacques. 2005. The Politics of Friendship. New York: Verso.

Feifel, H. 1959. The Meaning of Death. New York: McGraw-Hill Book Company, Inc.

Getz, A. 1995. "Makaziwe makes her mark”. Daily Dispatch. East London, S. Africa, May 25.

Gordon-Smith, George M. 2008. "Sympathetic observations: Widowhood, Spectatorship and Sympathy in the Fiction of Henry James". Master of Arts thesis, Brigham Young University.

Green, M. and Winkler, D. 1980. "Brain Death and Personal Identity". Philosophy and Public Affairs, 9, pp.105-133.

Huzayyin, Ahmad and Gyo"rgy Acsa'di. N.d. Research Monograph Series, no. 6. Cairo: Cairo Demographic Centre.

Igba Nkpe .1996. "Chapter II Igbo Widowhood Rituals and Practices" http://www.ub.uib.no/elpub/1996/h/506001/korieh/chima-Chapter-2.html

Kamm, F.M. 1998. Morality Mortality, Vol. 1. Oxford: Oxford University Press.

Kimani, Violet Nyambura. 2004. "Human Sexuality: Meaning and Purpose in Selected Communities in Contemporary Kenya". The Ecumenical Review, Vol.56 no.4.

Kirwen, Michael C. 1979. African Widows. New York: Orbis Books.

Kunda, A. 1995. "Pressure to ban sexual cleansing in Zambia". AIDS Analysis Africa, Vol.5 no.2. Abstract, Popline.

Limann, I. H. 2003. "Widowhood rites and the rights of women in Africa: The Ugandan experience". Faculty of Law, Makerere University, Kampala.

Lopata, H.Z. 1979. Women as Widows. New York: Elsevier.

Luginnah, I., D. Elkins, E.Maticka-Tyndale, T. Landry and Mathui M. 2005. "Challenges of a pandemic: HIV/AIDS related problems affecting Kenyan widows". Social Science \& Medicine, Vol.60 no.6, pp.1219-1228.

Luke, Nancy. 2001. "The Cultural Significance of Widowhood: Widow Inheritance and the Position of Luo Widows in the 1989 Kenya Census". Paper prepared for the Virtual Conference on African Households, Population Studies Centre, November 21-24, University of Pennsylvania. 
Makisi, Z. 1995. "Xhosa face cultural crisis". Daily Dispatch. East London, S. Africa, February 17.

Mwamwenda, T.S. 1995. Educational psychology: An African perspective. 2nd ed. Durban: Butterworths.

Mwamwenda, T.S. and L.A. Monyooe. 2007. "Status of Bridewealth in an African Culture". Journal of Social Psychology, Vol.137 No. 2.

NASCOP. 2005. AIDS in Kenya: background, projection, impact, interventions and policy. Nairobi: AIDS Control Unit, Ministry of Health, National Aids Control Council, Government printers.

Ndisi, John W. 1974. A Study in the Economic and Social Life of the Luo of Kenya. Lund: Berlingska Boktryckeriet.

Ntozi, James P.M. 1997. "Widowhood, remarriage and migration during the HIV/AIDS epidemic in Uganda". Health Transition Review, Supplement to Volume 7, pp.125-144.

Ocholla-Ayayo, A.B.C. 1976. Traditional Ideology and Ethics among the Southern Luo. Uppsala: Scandinavian Institute of African Studies.

--. 1996. Psychical, social and cultural issues relating to HIV/AIDS containment and transmission in Africa, with special reference to Kenya. Nairobi: Population Studies Research Institute, UON.

Odinga, Raila. 2008. "Circumcision and the Luo". http://nairobichronicle.wordpress.com/2008/10/07/raila-circumcision-and-theluo/ (accessed November 5, 2008).

Okeyo, Pala Achola. 1980. "Daughters of the Lakes and Rivers: Colonization and the Land Rights of Luo Women”. Etienne, M. and E. Leacock eds. Women and Colonization, pp.186-213. New York: Praeger.

Owen, M. 1994. "The world of the widow". People and the Planet, 3, pp.2-17.

Packer, T. 1995. The light of discovery. Boston: Charles E. Tuttle.

Potash, Betty. 1986a. "Widows in Africa: An Introduction". Potash, Betty Ed. Widows in African Societies, Stanford: Stanford University Press, pp.1-43.

--. 1986b. "Wives of the Grave: Widows in a Rural Luo Community". In Potash, Betty ed. Stanford: Stanford University Press, pp.44-65.

Simon, B. 1990. "Rethinking empowerment". Journal of Progressive Human Services, Vol.1 No.1, pp.27-40.

Sossou, M.A. 2002. "Widowhood practices in West Africa: the silent victims". International Journal of Social Welfare, 11, pp.201-209.

Tertilt Miche' le. 2005. "Polygyny, Fertility, and Savings". Journal of Political Economy, Vol.113 No.6.

The Centre on Housing Rights and Evictions (COHRE) \& Women and Housing Rights Programme (WHRP). 2006. "Fact Sheet Two: Women's Inheritance Rights".

http://www.iiav.nl/epublications//2006/Fact_Sheet_Two_Women's_Inheritanc e_Rights2.pdf

Zahedi, Ashraf. 2006. "State Ideology and the Status of Iranian War Widows". International Feminist Journal of Politics, Vol.8 No.2, pp.267-286. 